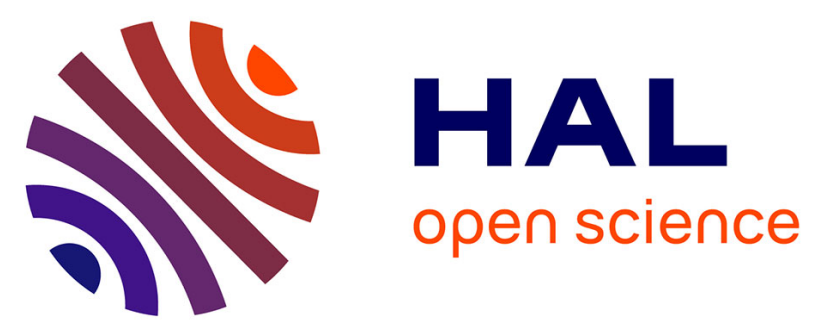

\title{
Internal Friction and Rigidity Modulus Change Associated with Structural Relaxation and Crystallization in Amorphous Zr67Fe33 Alloy
}

\author{
O. Yoshinari, Y. Iwata, M. Yamada, K. Tanaka
}

\section{- To cite this version:}

O. Yoshinari, Y. Iwata, M. Yamada, K. Tanaka. Internal Friction and Rigidity Modulus Change Associated with Structural Relaxation and Crystallization in Amorphous Zr67Fe33 Alloy. Journal de Physique IV Proceedings, 1996, 06 (C8), pp.C8-613-C8-616. 10.1051/jp4:19968131 . jpa-00254563

HAL Id: jpa-00254563

https://hal.science/jpa-00254563

Submitted on 1 Jan 1996

HAL is a multi-disciplinary open access archive for the deposit and dissemination of scientific research documents, whether they are published or not. The documents may come from teaching and research institutions in France or abroad, or from public or private research centers.
L'archive ouverte pluridisciplinaire HAL, est destinée au dépôt et à la diffusion de documents scientifiques de niveau recherche, publiés ou non, émanant des établissements d'enseignement et de recherche français ou étrangers, des laboratoires publics ou privés. 


\title{
Internal Friction and Rigidity Modulus Change Associated with Structural Relaxation and Crystallization in Amorphous $\mathrm{Zr}_{67} \mathrm{Fe}_{33}$ Alloy
}

O. Yoshinari, Y. Iwata, M. Yamada and K. Tanaka

Department of Materials Science and Engineering, Nagoya Institute of Technology, Nagoya 466, Japan

\begin{abstract}
The internal friction and the rigidity modulus of an amorphous $\mathrm{Zr}_{67} \mathrm{Fe}_{33}$ alloy have been measured in an inverted torsion pendulum apparatus with a frequency range of $0.3-2 \mathrm{~Hz}$. The rigidity modulus increases irreversibly with the annealing which suggests a two-step structural relaxation. It is clarified that the internal friction due to the structural relaxation and the crystallization depends on the heating rate and the vibrational frequency. It is suggested that the internal friction has a "transient component" which is proportional to the amount of structural change during one period of the vibration.
\end{abstract}

\section{Introduction}

Internal friction is known to be structure-sensitive and has been used to investigate the structural relaxation, the glass transition and the crystallization of amorphous alloys. Various mechanisms have been proposed for these phenomena based on mechanical models associated with anelasitc and/or viscoelastic solids[1]-[3]. In the present paper, we report the behaviour of the internal friction and the rigidity modulus of an amorphous $\mathrm{Zr}_{67} \mathrm{Fe}_{33}$ alloy and show that a mechanism other than such mechanical models should also be operative for the structural relaxation and the crystallization of this alloy.

\section{Experimental Procedures}

Amorphous $\mathrm{Zr}_{67} \mathrm{Fe}_{33}$ alloy was made by melt-spinning method. A ribbon-shape specimen, with $32 \mu \mathrm{m}$ thickness and $1 \mathrm{~mm}$ width, was cut into $30-50 \mathrm{~mm}$ in length for the internal friction measurements. Internal friction was measured in an inverted torsion pendulum. The apparatus, originally designed for wire specimens with about $1 \mathrm{~mm}$ in diameter, was improved for measuring thin specimens; a specimen holder is made of aluminium, a connection rod between the specimen holder and the inertia is a thin pipe of stainless steel and the vibration is detected by an optical lever system. The measurements were performed at a constant heating or cooling rate of $1-10 \mathrm{~K} / \mathrm{min}$ over a temperature range $300 \mathrm{~K}-750 \mathrm{~K}$ with a vibrational frequency of $0.3-2 \mathrm{~Hz}$.

\section{Results}

Figure 1 shows the internal friction and the corresponding frequency change measured during a constant heating of $1 \mathrm{~K} / \mathrm{min}$. The internal friction $Q^{-1}$ gradually increases with temperature and shows a peak at $643 \mathrm{~K}$ $\left(T_{\mathrm{P}}\right)$. The frequency $f\left(f^{2}\right.$ is proportional to the rigidity modulus, $\left.G\right)$ begins to increase at $400 \mathrm{~K}$ and attains a maximum around $520 \mathrm{~K}$ and then decreases. It also shows a step increase corresponding to the internal friction peak. The inset in Fig. 1 is the enlargement around $T_{\mathrm{P}}$; the logarithm of $Q^{-1}$ is plotted. It shows that $Q^{-1}$ increases rapidly at $630 \mathrm{~K}$ where $f$ begins to increase. To examine the relation between these changes and the structural change of the specimen, the X-ray diffraction (XRD) was measured using $\mathrm{Cu}-\mathrm{K} \alpha$ radiation for specimens annealed in the internal friction apparatus with the same heating condition. Figure 2 shows the $\mathrm{XRD}$ spectra for specimens which have been heated up to various temperatures. It is shown that the specimen maintains the amorphous structure at $627 \mathrm{~K}$ just below $T_{\mathrm{p}}$ and it crystallizes above $T_{\mathrm{P}}$. Therefore, it is suggested that the peak is associated with the crystallization which takes place at $630 \mathrm{~K}$ for the heating 


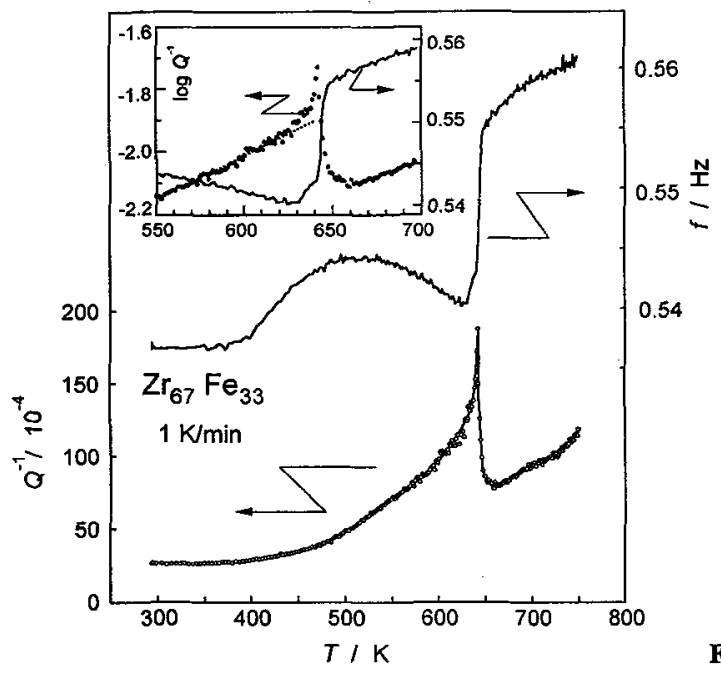

Figure 1: Internal friction and vibrational frequency of $a-\mathrm{Zr}_{67} \mathrm{Fe}_{33}$ alloy measured on a constant heating rate of $1 \mathrm{~K} / \mathrm{min}$.

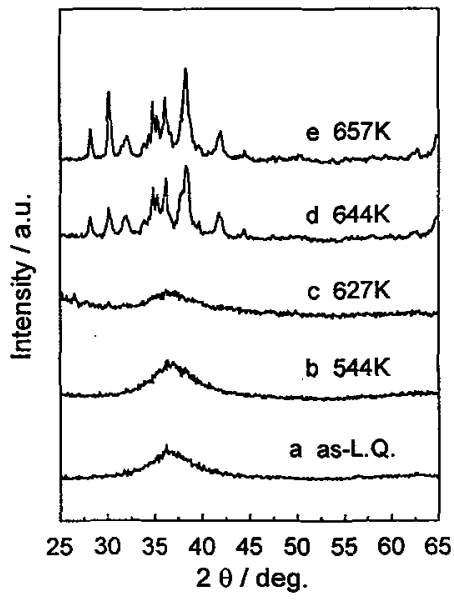

Figure 2: XRD spectra for specimens which have been annealed in the torsion-pendulum on linear heating $(1 \mathrm{~K} / \mathrm{min})$. The temperatures in the figure indicate the upper limit of the heating.

condition of $1 \mathrm{~K} / \mathrm{min}$.

In order to clarify the nature of the changes in $Q^{-1}$ and $f$, heating and cooling measurements were repeated for a specimen with rasing the upper limit of the heating (Fig. 3). The internal friction on cooling is omitted in Fig. 3(a), because it shows almost the same curve as that on the next heating run. On proceeding the annealing, $Q^{-1}$ above $400 \mathrm{~K}$ decreases and the crystallization peak disappears after the crystallization. On the other hand, $f$ shows rather complex feature. The increase in $f$ above $380 \mathrm{~K}$ observed on the first heating run does not recover on the subsequent cooling. In contrast, the difference between the second heating and cooling runs is small. To illustrate the change in $f$ corresponding to the annealing, the frequency at $300 \mathrm{~K}$, $f_{300 \mathrm{~K}}$, is plotted against the annealing temperature $T_{\mathrm{a}}$, which is defined as the maximum temperature attained on the previous heat cycle (Fig. 4). The broken line in the figure is estimated from the difference between the data on the first cooling and heating runs. Figure 4 clearly shows that the amorphous structure changes via two different stages; one is in a range between 380 and $500 \mathrm{~K}$ and the otrher is in a range above $600 \mathrm{~K}$.

Figures 5 shows the heating rate dependence of $Q^{-1}$ spectra. The crystallization peak increases and
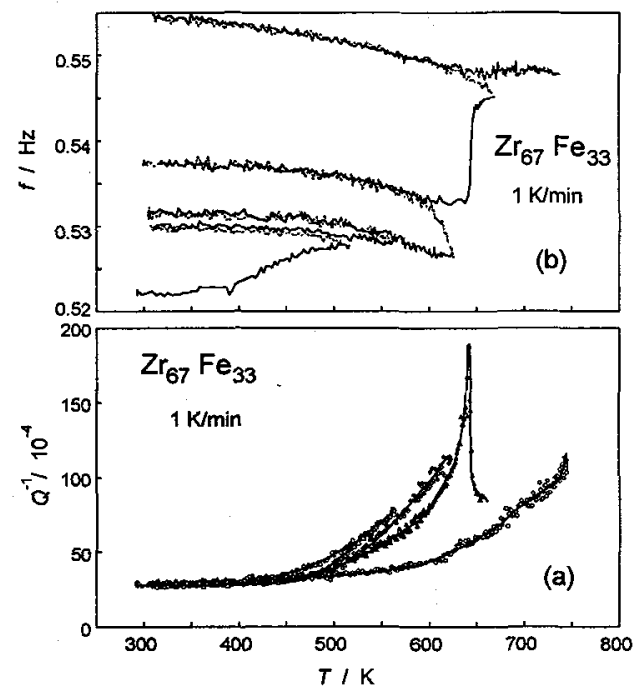

Figure 3: Internal friction (a) and vibrational frequency (b) observed on repeated thermal cycling. shifts toward higher temperatures with the increase in the heating rate. The shift of the peak is consistent with the fact that the crystallization temperature is dependent on the heating rate. The activation energy of the crystallization is obtained to be $530 \mathrm{~kJ} / \mathrm{mol}$ from the

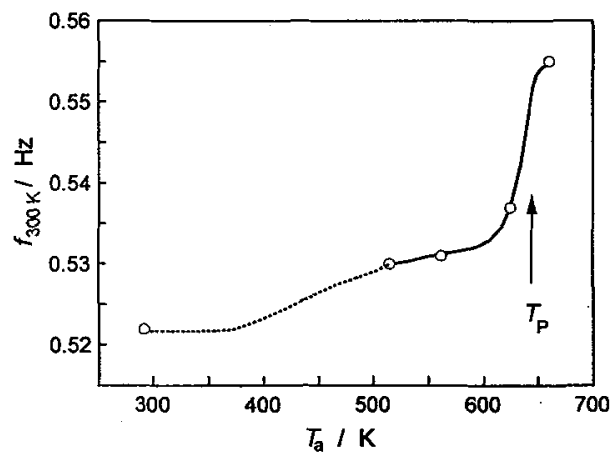

Figure 4: The effect of the annealing on the vibrational frequency at $300 \mathrm{~K}, f_{300 \mathrm{~K}}$. The values of $f_{300 \mathrm{~K}}$ are taken from Fig 3(b). The broken line is estimated from the difference between the first heating and cooling runs. 
Kissinger-plot: $\ln \left[\dot{T} / T_{\mathrm{P}}^{2}\right]$ are plotted against $T_{\mathrm{P}}{ }^{-1}$, where $\dot{T}$ is the heating rate. The internal friction is also dependent on the measuring frequency. Figure 6 shows that the crystallization peak is higher for lower $f$ and the tail of the peak has almost the same feature. In Fig. 7, the $Q^{-1}$ at $T_{\mathrm{P}}$ and $500 \mathrm{~K}$ with a suitable background $\left(Q_{\mathrm{B}}{ }^{-1}\right)$ subtracted are plotted against $\dot{T} / f$ which corresponds to the temperature change during the one cycle of the measuring vibration.

\section{Discussion}

The internal friction observed in the present investigation depends on the heating rate $\dot{T}$ and the measuring frequency $f$, as shown in Figs. 5 and 6. Although Myung reported $f$ dependence of the peak height in $a$-Fe-Mn-P alloys [4], there seems to be no work on the $\dot{T}$ dependence of the internal friction in amorphous metals. As shown in Fig. 7, $Q^{-1}$ has a large amount of magnitude even when the data are extrapolated to $\dot{T} / f=0$. Such a component should be observed when there is no structural change during the measurement. We will call it an "equilibrium component", $Q_{\mathrm{E}}{ }^{-1}$ in the following. The internal friction furthermore has an excess component for $\dot{T}$ $>0$. We call it a "transient component", $Q_{\mathrm{r}^{-1}}$.

Such a transient internal friction has also been observed for the cases where the internal structure changes with the temperature, e.g. the martensitic transformation of the shape memory alloys [5] and the hydride precipitation in metal-hydrogen systems[6]. The internal friction is considered to be associated with the elastic anisotropy of the transformation products. If such transformation occurs under an anisotropic stress, transformation products with favoured orientation will predominantly be formed and yield an inelastic strain, which is the origin of the $Q_{\mathrm{T}^{-1}}$. The magnitude of $Q_{\mathrm{T}}{ }^{-1}$ is proportional to the amount of the transformation during one period of the $Q^{-1}$ measurement;

$$
Q_{\mathrm{T}}^{-1}=A(\mathrm{~d} x / \mathrm{d} t) / f=A(\mathrm{~d} x / \mathrm{d} T)(\dot{T} / f),
$$

where $A$ is a proportional constant and $x$ is a parameter which expresses the amount of the structural change and takes values of $x=0$ and $x=1$ before and after the structural change, respectively. Therefore, if the quantity $\mathrm{d} x / \mathrm{d} T$ is not much dependent on $\dot{T}, Q_{\mathrm{T}}{ }^{-1}$ will be proportional to $\dot{T} / f$. It is noted that $Q_{\mathrm{T}}^{-1}$ will be hardly observed at high frequency measurements because of its $1 / f$ dependence and thus the observed internal friction in such measurements consists of the equilibrium components, $Q_{\mathrm{E}}^{-1}$.

In the following we discuss the transient component associated with the structural relaxation of the amorphous alloys. We assume here that the amount of the structural relaxation $x$ is expressed as follows;

$$
x=1-\exp \left[-(t / \tau)^{\beta}\right],
$$

where $\tau$ is the relaxation time and $\beta$ is an experimental parameter between 0 and 1 . It is known that the structural relaxation in many amorphous and glassy systems can be described by Eq.(2), which is generally called the Kohlrausch relaxation[7]. Although Eq.(2) is applicable for the structural relaxation in an 
isothermal condition, it can readily be extended to a nonisothermal condition by considering the temperature or time dependence of $\tau$. The quantity $x$ and its time-derivative are then given as follows:

$$
\begin{aligned}
x & =1-\exp \left[-\left(\int \mathrm{d} t / \tau\right)^{\beta}\right] \\
\mathrm{d} x / \mathrm{d} t & =[\beta(1-x) / \tau]\left(\int \mathrm{d} t / \tau\right)^{\beta-1}
\end{aligned}
$$

For the purpose of illustrating $Q_{\mathrm{T}}{ }^{-1}$ spectra associated with the structural relaxation, we calculate the temperature dependence of $\mathrm{d} x / \mathrm{d} t$. For the sake of simplicity we assume that $\beta$ is independent of temperature and the relaxation time is given by a simple form $\tau=\tau_{0} \exp (E / R T)$. In Fig 8, the experimentally obtained $Q_{\mathrm{T}}^{-1}$ spectra around the temperature of the structural relaxation are compared with Eq. 3 calculated with suitable parameters. $Q_{\mathrm{T}^{-1}}$ is evaluated by subtracting a $Q_{\mathrm{E}}^{-1}$ spectrum which is obtained by extrapolating the spectra at finite heating rates to zero heating rate. The calculated spectra for 1 and $2 \mathrm{~K} / \mathrm{min}$ show maxima below $600 \mathrm{~K}$ while experimental ones only monotonically increase. This may be explained as follows. In the calculation we assumed only one type of the structural relaxation, which shows a peak in $\mathrm{d} x / \mathrm{d} t$ versus $T$ curve. According to the result shown in Fig. 4, the structural relaxation of the present alloy shows two distinct steps. The first relaxation finishes around $600 \mathrm{~K}$ and the second one begins above $600 \mathrm{~K}$. Therefore, the

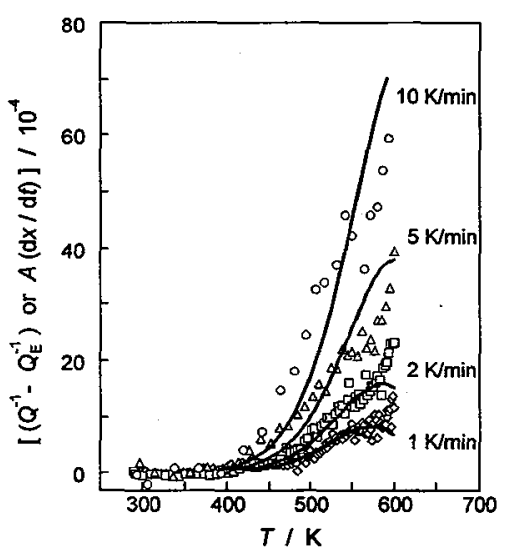

Figure 8: Comparison between experimental and calculated transient component for the structural relaxation. Following parameters have been used for the calculation: $\tau_{0}=10^{-10}$ $\mathrm{s}^{-1}, E=145 \mathrm{~kJ} / \mathrm{mol}, \beta=0.4$ and $A=6.0$. discrepancy between the calculated and experimental spectra for the heating rates of 1 and $2 \mathrm{~K} / \mathrm{min}$ around $600 \mathrm{~K}$ can be attributed to the beginning of the second structural relaxation. It should be noted that the parameters used for the above calculation are not unique; similar fitness may also be obtained with other sets of parameters. It is necessary to perform more detailed experiments in isothermal conditions in order to obtain more precise values of these parameters.

Finally, we briefly discuss the equilibrium component. As shown in Fig.4, the rigidity modulus almost remains constant at the range between $T_{\mathrm{a}}=500 \mathrm{~K}$ and $600 \mathrm{~K}$. This suggests that the structural relaxation does not occur at this temperature range. On the other hand, a large amount of $Q^{-1}$ is observed at the same temperature range. As discussed above, the transient component should not be observed when the internal structure does not change during the measurement. The observed $Q^{-1}$ may be the equilibrium component which is caused by the anelastic behaviour of the amorphous structure itself. The normal temperature dependence of the rigidity modulus (negative temperature coefficient of $f$ ) between 500 and $600 \mathrm{~K}$ (see Fig. $3(b)$ ), also supports such a possibility.

\section{Conclusion}

The low frequency internal friction and elastic modulus have been measured for an amorphous $\mathrm{Zr}_{67} \mathrm{Fe}_{33}$ alloy. It is observed that the internal friction is dependent on the heating rate and the measuring frequency. This is because the internal friction consists of two components; namely transient and equilibrium. The transient component is caused by the proceeding of the structural relaxation or crystallization of the alloy during the measurement of the internal friction. The equilibrium component is originated from the anelastic behaviour of the amorphous structure. It is also observed that the rigidity modulus changes irreversibly on heating in two different temperature ranges. These changes are considered to be due to the structural relaxation.

\section{References}

[1] Chen, H. S., Leamy, H. J. and Barmats, M., J. Non-Cryst. Solids 5 (1971) 444-448.

[2] Morito, N. and Egami, T., Acta Metall. 32 (1984) 603-613.

[3] Sinning, H. -R. and Haessner, F., J. Non-Cryst. Solids 93 (1987) 53-66.

[4] Wha-Nam Myung, Sang-Jo Kim, Dal-Hwan Jang, Okumura, H., Inoue, A., and Masumoto, A., J. NonCryst. Solids 150 (1992) 406-412.

[5] Postnikov, V. S, Sharshakov, I. M. and Komarov, V. G., Fiz. Met. Metallov. 33 No. 1 (1972) 222-224.

[6] Yoshinari, O. and Koiwa, M., Acta Metall. 30 (1982) 1987-1991.

[7] see for example: Phililps, J. C., J. Non-Cryst. Solids 182 (1995) 155-161. 